\title{
Comércio e serviços de rua como manifestações do circuito inferior da economia em dois bairros de Salvador, Bahia
}

\author{
Street trade and services as manifestations of the lower circuit of the economy in two \\ neighborhoods of Salvador, Bahia
}

\begin{abstract}
Angelo Serpa
Professor titular de Geografia Humana da Universidade Federal da Bahia, Brasil

Bolsista de produtividade em pesquisa do CNPq, nível 1B

angeloserpa@hotmail.com
\end{abstract}

Wellington Leite

Bolsista de Iniciação Científica da Fundação de Amparo à Pesquisa do Estado da Bahia - FAPESB

(2019-2020)

Graduando do curso de Geografia da Universidade Federal da Bahia, Brasil wellingtonleite.well@,gmail.com

\begin{abstract}
Juliana Machado
Bolsista de Iniciação Científica do Conselho Nacional de Desenvolvimento Científico e Tecnológico - CNPq (2019-2020)

Graduanda do curso de Geografia da Universidade Federal da Bahia, Brasil juliana.machadogeo@outlook.com
\end{abstract}

\begin{abstract}
Resumo
Neste artigo são apresentados os resultados de uma pesquisa conduzida junto aos comerciantes e prestadores de serviços de rua em dois bairros de Salvador no ano de 2019. Foram realizadas, a partir de uma amostragem não probabilística por cotas e com curva de saturação de respostas, 18 entrevistas no bairro do Rio Vermelho e 15 entrevistas no bairro da Graça. Objetivou-se caracterizar o perfil e as trajetórias dos comerciantes e prestadores de serviços de rua, assim como identificar as relações entre o circuito superior e o circuito inferior da economia (SANTOS, 2004), estabelecidas a partir da atuação dos empreendedores de rua alcançados pela pesquisa. Um critério fundamental para a escolha dos dois bairros foi a implementação de operações recentes de requalificação urbana em seus espaços públicos. São, ambos, bairros residenciais, com moradores de renda média a alta, que apresentam uma significativa presença de comércio e serviços de rua. Embora haja especificidades em cada um dos recortes analisados, percebe-se que em ambos há uma complementaridade entre os dois circuitos da economia, evidenciada, sobretudo, na localização do comércio e dos serviços de rua. Os comerciantes/prestadores de serviço apresentam, em geral, certa flexibilidade em sua jornada de trabalho, adaptando o período de trabalho às especificidades de quem trabalha na rua. Tanto no Rio Vermelho como na Graça, aqueles comerciantes/prestadores de serviço que dispõem de estruturas fixas (quiosques e barracas metálicas) são em geral cadastrados e recolhem taxas, além de ter uma jornada de trabalho melhor distribuída na semana e menos dificuldades no cotidiano.
\end{abstract}

Palavras-chave: comércio de rua, serviços de rua, circuito inferior da economia, bairro, requalificação urbana, Salvador. 


\begin{abstract}
This article presents a survey conducted with street vendors and service providers in two neighbourhoods of Salvador in 2019. From a non-probabilistic sampling by quotas and with a response saturation curve, 18 interviews were performed in the neighbourhood of Rio Vermelho and 15 in the neighbourhood of Graça. The objective was to characterize the profile and trajectories of street vendors and service providers and identify the relationships between the upper circuit and the lower circuit of the economy (SANTOS, 2004), established from the performance of the street entrepreneurs reached by the research. A fundamental criterion for choosing the two neighbourhoods was implementing recent urban redevelopment operations in their public spaces. Both are residential neighbourhoods, with medium to high-income residents, who have a significant commerce and street services presence. Although there are specificities in each of the analyzed sections, it can be seen that there is a complementarity between the two circuits of the economy, evidenced, above all, in the location of commerce and street services. In general, sellers/service providers have certain flexibility in their working hours, adapting the working period to the specificities of those who work on the street. Both in Rio Vermelho and Graça, those merchants/service providers who have fixed structures (kiosks and metal tents) are generally registered. They collect fees and have a better-distributed workday during the week and fewer difficulties in daily life.
\end{abstract}

Key-words: street commerce, street services, the lower circuit of the economy, neighbourhood, urban requalification, Salvador.

\title{
1. INTRODUÇÃO
}

A pesquisa que originou esse artigo teve como objetivo caracterizar os processos socioespaciais relacionados ao comércio e aos serviços de rua e às situações de conflitos ou resistências geradas a partir da requalificação de espaços públicos na metrópole soteropolitana, tendo como recortes os bairros do Rio Vermelho, localizado na Orla Atlântica, e da Graça, no centro de Salvador-Bahia (Figura 1). Pretendeu-se caracterizar também o perfil e as trajetórias dos comerciantes e prestadores de serviços de rua, assim como identificar as relações entre o circuito superior e o circuito inferior da economia (SANTOS, 2004), estabelecidas a partir da atuação dos empreendedores de rua alcançados pela pesquisa nestes recortes específicos.

Quando nos referimos a comércio e serviços de rua estamos considerando produtos e serviços vendidos/oferecidos em quiosques, bancas, barracas, tabuleiros, estruturas desmontáveis, no fundo de carros e caminhonetes estacionados, em lonas no chão etc. Em Salvador, essas atividades estão presentes não só em centralidades de comércio e serviços do circuito superior, mas também nas praias e nos bairros residenciais da cidade. Em trabalho anterior (SERPA; LEITE; MACHADO, 2019), constatamos que a compreensão da dinâmica dos dois circuitos da economia urbana (SANTOS, 2004) é a chave para entender o que ocorreu com os comerciantes/prestadores de serviços de rua no entorno da Estação da Lapa ${ }^{1}$, após sua requalificação.

\footnotetext{
${ }^{1}$ Maior estação de transbordo da cidade, nó de articulação de significativo número de linhas de ônibus e o metrô de Salvador, localizada no centro antigo da cidade.
} 
Esses empreendedores, em geral localizados no entorno de estações de transbordo, shoppings e grandes lojas, expressam na paisagem a indissociabilidade dos dois circuitos da economia, a centralidade sendo criada a partir da atração exercida pelo circuito superior. Essa indissociabilidade também pode ser observada entre os "barraqueiros" da praia de Piatã e os depósitos e distribuidores de bebidas, demonstrando a grande dependência entre o comércio e os serviços de rua e o comércio atacadista/as empresas distribuidoras do circuito superior (SERPA; LEITE; MACHADO, 2019). Ainda que, no caso de algumas dessas empresas, possa-se pensar em um circuito superior "marginal", devido aos níveis de técnica e capital envolvidos, assim como ao porte dos estabelecimentos e à mão de obra pouco especializada ${ }^{3}$ (SANTOS, 2004).

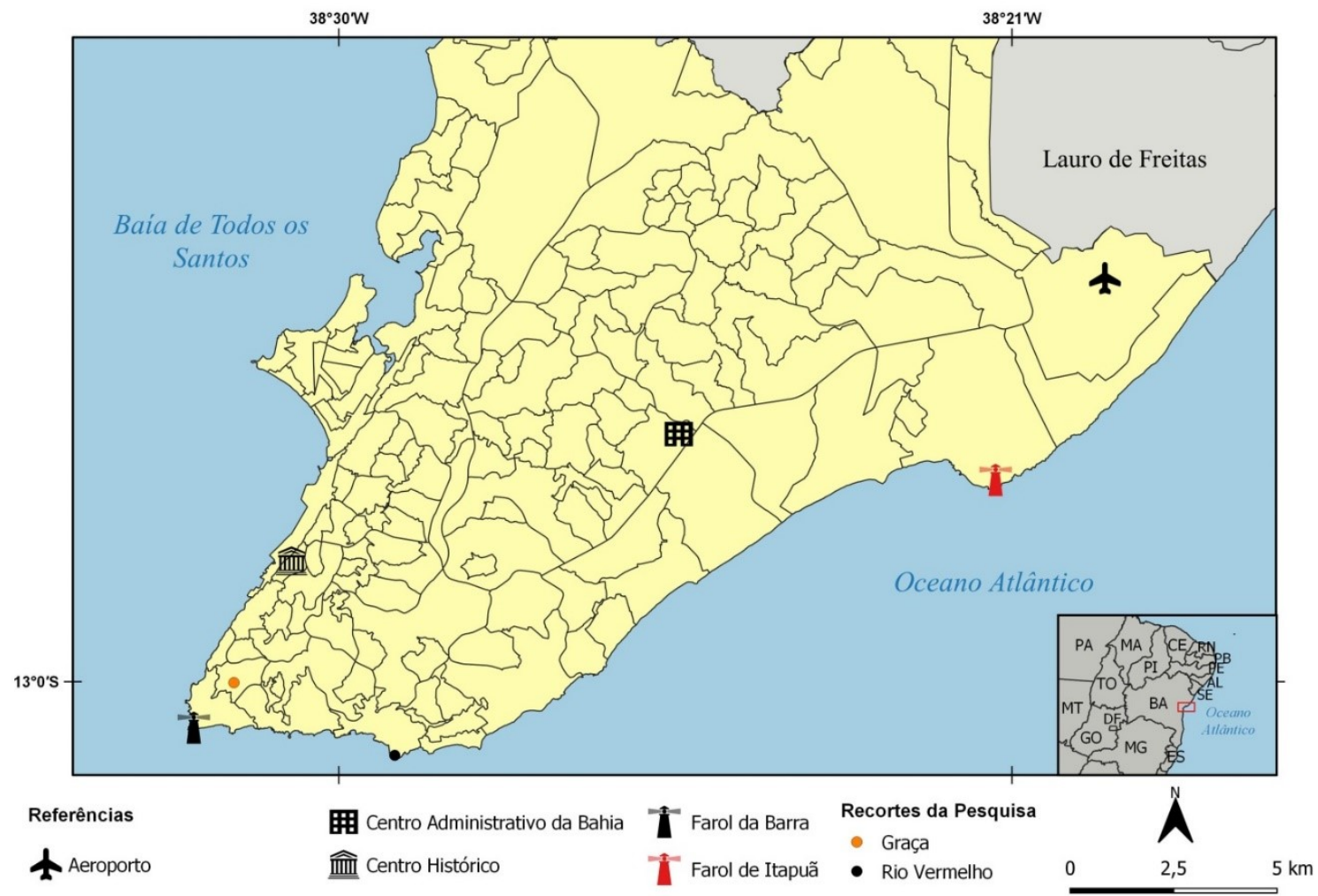

Figura 1 - Localização dos recortes da pesquisa Fonte: Autores (2020).

Ao assumirmos o recorte de bairro nos levantamentos apresentados nesse artigo, buscou-se avaliar se haveria diferenças significativas em relação aos recortes analisados no primeiro ano de

\footnotetext{
${ }^{2}$ Esses empreendedores são, em sua maioria, homens, conhecidos popularmente como "barraqueiros" porque trabalham com estruturas semifixas, que incluem equipamentos como toldos, sombreiros, cadeiras e mesas; geralmente de pequeno porte, esses estabelecimentos vendem em geral bebidas que variam de cerveja e refrigerantes a água mineral e água de coco (SERPA; LEITE; MACHADO, 2019, p. 980).

${ }^{3}$ Interessante constatar que mesmo o setor de bebidas pode ser visto como pertencente ao circuito superior marginal em sua totalidade, como mostram as pesquisas de Nucci (2016) em Buenos Aires, sobre o setor de bebidas gasosas e águas com sabor. Para a autora, essas firmas se caracterizam por apresentar formas de produção menos modernas do ponto de vista técnico e organizacional, sendo resultado de divisões de trabalho pretéritas, mas, ao mesmo tempo, representam também atividades emergentes e modernas (NUCCI, 2016).
} 
nossas pesquisas, o entorno de uma grande estação de transporte coletivo no centro antigo de Salvador e a praia de Piatã (incluindo sua orla requalificada). Um critério fundamental para a escolha dos dois bairros foi a implementação de operações recentes de requalificação urbana (no Rio Vermelho, na Rua da Paciência/Orla do bairro e no Largo da Mariquita e, na Graça, na Avenida Euclides da Cunha e no Largo da Graça). São, ambos, bairros residenciais, com moradores de renda média a alta, que apresentam uma significativa presença de comércio e serviços de rua, o Rio Vermelho se caracterizando também como uma centralidade boêmia e de lazer/turismo ${ }^{4}$ da cidade, com muitos bares, restaurantes, casas de show etc. O bairro da Graça, por sua vez, apresenta quantidade significativa de estabelecimentos comerciais e de serviços do circuito superior, incluindo supermercados, lavanderias e farmácias de grandes redes, petshops, laboratórios de imagem e análises clínicas, clínicas médicas e odontológicas, academias de ginástica, pizzarias e restaurantes, assim como um grande hospital (Hospital Português).

Foram realizadas, a partir de uma amostragem não probabilística por cotas e com curva de saturação de respostas, 18 entrevistas no bairro do Rio Vermelho e 15 entrevistas no bairro da Graça, em 2019, antes, portanto, da eclosão da pandemia de COVID-19, buscando englobar toda a diversidade do comércio e dos serviços de rua abarcada por nossos levantamentos. Quando as respostas dos entrevistados se tornaram repetitivas e redundantes, encerramos as entrevistas em ambos os recortes e nos voltamos para a sistematização dos dados obtidos e a produção de tabelas e gráficos, obtendo-se uma primeira representação do perfil dos empreendedores de rua e de seus negócios. Posteriormente, analisamos qualitativamente as falas desses comerciantes, buscando entender as trajetórias e necessidades desses sujeitos.

\section{O BAIRRO DA GRAÇA}

\subsection{O perfil dos comerciantes e prestadores de serviços de rua do bairro}

Quem são as pessoas que trabalham nas ruas do bairro da Graça? Nossas pesquisas revelaram que mais da metade dos entrevistados são homens, que, frequentemente, vendem frutas e verduras compradas em feiras populares e mercados atacadistas, colocando os seus produtos geralmente no fundo do carro ou expostos nas calçadas; trabalham também nas bancas de revistas ou prestando serviços de chaveiro e sapateiro. As mulheres identificadas são da mesma família e trabalham com o mesmo produto, em locais diferentes no bairro: feijão-verde.

\footnotetext{
${ }^{4}$ Conhecido por sua importância histórica na formação da cidade, o bairro do Rio Vermelho hoje abriga uma das principais centralidades de lazer e turismo de Salvador, onde a antiga tradição pesqueira, os teatros e os monumentos convivem com os bares, casas de show e uma intensa vida noturna, atraindo aqueles que buscam entretenimento na cidade.
} 
Quando analisamos a figura 2 e percebemos a distância percorrida por estes comerciantes e prestadores de serviços, a partir de seus bairros de residência (com exceção do Rio Vermelho e Brotas, todos bairros populares e periféricos em Salvador), outras questões emergem dos levantamentos realizados: Qual a influência que o bairro da Graça exerce para estes trabalhadores? Por que não vendem ou prestam serviços em seus próprios bairros ou lugares mais próximos? Existem benefícios específicos para quem trabalha na Graça?

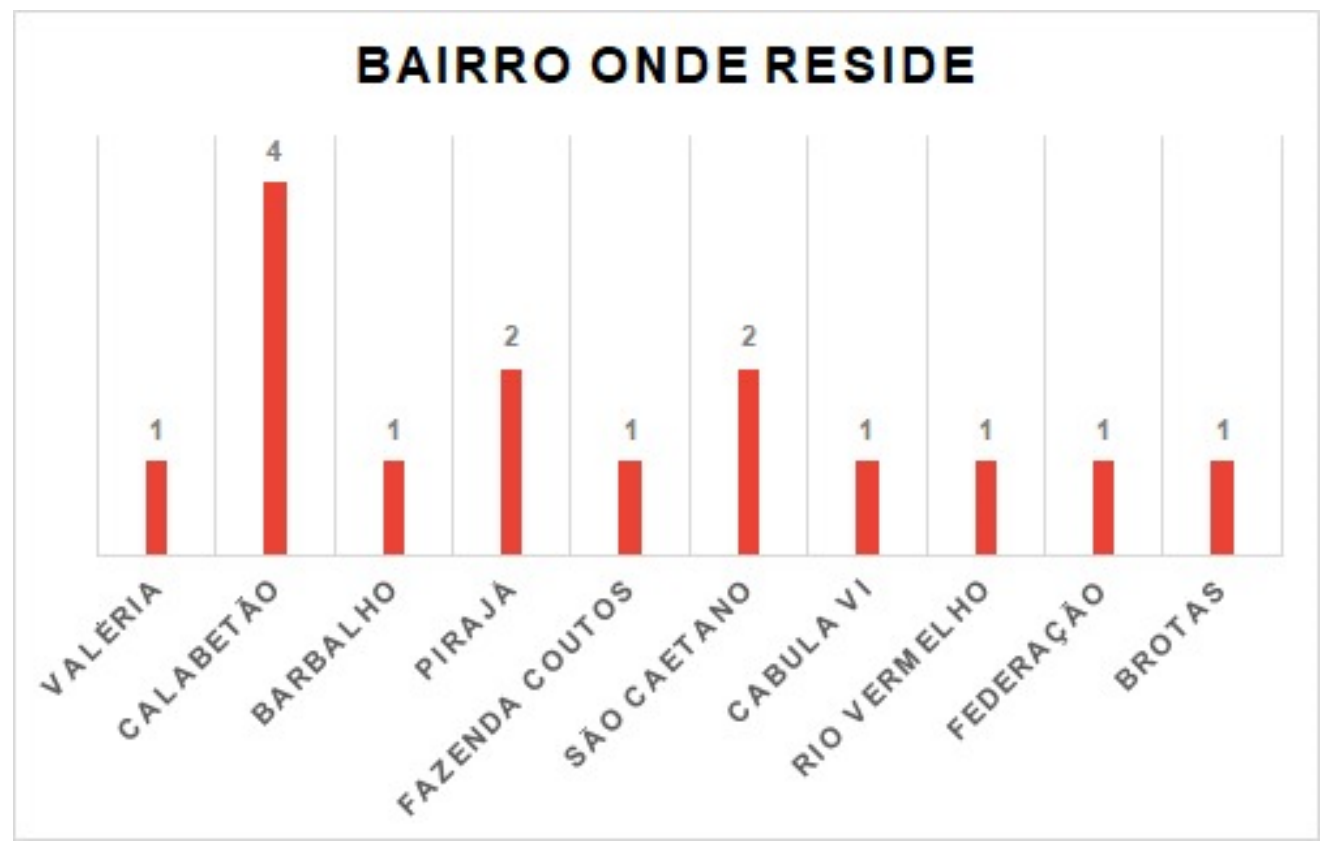

Figura 2 - Bairro onde reside.

Fonte: Pesquisa de Campo, 2019. MACHADO, 2020, elaboração própria.

Os entrevistados revelam que o bairro da Graça não era o local inicialmente escolhido para fixarem seu ponto, surgindo como uma opção para estes trabalhadores pelo "acaso" de procurarem um local para vender ou pelo apoio de parentes. Percebe-se que trabalhar em seus próprios bairros ou lugares próximos é uma opção descartada pela maioria dos entrevistados, por conta da concorrência e por não conseguirem vender seu produto no preço desejado, como se percebeu na fala do Sr. N. B. ${ }^{5}$ : "nos outros lugares, o preço do lanche... Ninguém vai dar o preço que a gente quer... Aqui a gente vende de cinco reais". Por outro lado, ao se optar pelos bairros da Graça e do Rio Vermelho esses comerciantes/prestadores de serviços de rua acabam por evitar também as áreas com ainda mais centralidade na cidade como o centro antigo e a centralidade do Iguatemi/Camaragibe já que, como constatado por Montenegro (2016), agentes menos capitalizados devem enfrentar custos muito elevados em relação ao seu nível de capitalização para ter acesso a uma localização mais central.

\footnotetext{
${ }^{5}$ Todos os entrevistados tiveram sua identidade preservada neste artigo e são identificados com iniciais maiúsculas fictícias.
} 
O bairro da Graça torna-se uma opção viável para trabalhadores venderem seus produtos com o preço desejado, mas, se observa também que, durante as entrevistas, o ganho/lucro, tanto diário como mensal, foi um assunto delicado para os empreendedores: alguns alegam que não fazem um controle das despesas, outros preferiram não comentar seus ganhos e gastos diários ou mensais e outros apenas nos forneceram uma estimativa.

Nossas pesquisas mostraram também outra faceta dos comerciantes e prestadores de serviços do bairro da Graça - a baixa escolaridade de quem trabalha no recorte pesquisado: a maioria cursou apenas e parcialmente o fundamental e alguns poucos concluíram o ensino fundamental ou médio. Muitos começaram na atividade atual (ou similar) muito cedo e não pretendem retomar os estudos. O bairro da Graça apresenta uma predominância de comerciantes e prestadores de serviços de rua com idades entre 20 e 59 anos de idade, alguns com tempo de trabalho entre um e dez anos e a maioria (mais da metade) com experiência na atividade há mais de uma década (alguns com mais de 20 anos de experiência trabalhando nesse tipo de atividade).

\subsection{Análise das redes de produção e distribuição dos comerciantes e prestadores de serviços do bairro da Graça}

Durante as saídas de campo, em horários e dias variados, observou-se empreendedores de rua vendendo frutas e verduras, trabalhando em bancas de revistas e comercializando produtos diversos, como eletrônicos e artigos variados. A escolha do produto ou da atividade atual é consequência de um conhecimento prévio, através de parentes ou amigos que auxiliam os trabalhadores. O local onde compram esses produtos foi também uma questão importante durante a realização das entrevistas: feiras populares e centrais de abastecimento são citadas ao longo da pesquisa, geralmente pelos comerciantes que vendem frutas e verduras.

Através das respostas obtidas sobre o local onde se abastecem, encontramos um cotidiano de dificuldades - a necessidade de acordar cedo para garantir seus produtos, lidar com os frequentes assaltos e o modo como transportam suas mercadorias (através de carros fretados/próprios ou ônibus):

\footnotetext{
Eu saio de casa quatro e meia da manhã e aí quando dá cinco horas, os ônibus começam a passar e aí eu pego o ônibus, chego na feira, compro mercadoria e aí eu coloco dentro do carro e venho pra Graça (Sra. B. P., entrevista realizada em 30 de novembro de 2019).

A gente paga carreto ou quando não paga carreto, traz no ônibus. O carreto cobra vinte ou trinta reais (Sr. F. B., entrevista realizada em 11 de dezembro de 2019).
}

Os trabalhadores que vendem frutas e verduras geralmente trabalham nas calçadas, sentados ou usando caixotes para expor seus produtos; alguns se utilizam do fundo do carro para 
vender suas mercadorias com o intuito de não precisar colocá-las na calçada e, assim, evitar atrito com moradores e as operações de descarga dos produtos:

No fundo do carro! Porque não bota no chão e a gente não pega muito peso, não tem esse negócio de colocar no chão, ficar armando e desarmando, entendeu? (Sr. T. T., entrevista realizada em 21 de novembro de 2019).

Eu escolhi esse ponto porque fica próximo ao mercado, aí faz um movimentozinho e eu também estou aqui debaixo da árvore, que está mais acomodado para mim [...] Eu não estou tomando o espaço do caminho de ninguém e a árvore me ajuda, protege do sol e da chuva (Sra. B. P., entrevista realizada em 30 de novembro de 2019).

Os moradores não aceitam a gente colocar coisas no chão. Eu estou no carro porque qualquer coisa o pessoal começar a reclamar... Pego, fecho e vou embora. Mais fácil de você resolver as coisas (Sr. D. C., entrevista realizada em 01 de novembro de 2019).

O trabalho em uma banca de revistas revela uma relação de consignação, existente entre os vendedores e distribuidoras, além de uma queixa recorrente nesta atividade: a queda nas vendas de revistas e, consequentemente, a necessidade de encontrar outros produtos para ajudar nos lucros:

É distribuidora, [...] É consignado. O que não vende, devolve. Tem que diversificar porque revista, por conta da internet, caiu muito e hoje existe um acesso mais fácil através do computador, então a banca precisa diversificar, colocar outros produtos porque, senão, não vende [...] Eu imprimo boleto, imprimo os documentos que trazem, aí vai ajudando (Sr. G. T., entrevista realizada em 14 de dezembro de 2019).

A revista começou a cair, então implantamos o cafezinho, né? Botamos o cafezinho, estamos vendendo um lanchezinho. Um pouco, mas estamos vendendo. Devagarzinho e vendemos tabacaria, tudo para ajudar a pagar as contas (Sr. H. B., entrevista realizada em 28 de dezembro de 2019).

\subsection{Sobre a relação dos comerciantes e prestadores de serviços com o bairro da Graça, os moradores, a fiscalização e a requalificação}

Constatou-se certa "fixidez" nos locais escolhidos pelos empreendedores para estabelecer o ponto, vendendo seus produtos em estruturas móveis estacionadas, como o fundo dos carros, ou expostos no chão com auxílio de caixotes, montados no começo do dia e retirados à noite, ou, ainda, em barracas de metal, para quem trabalha em bancas de revistas, os chaveiros/sapateiros e alguns poucos vendedores de frutas, havendo, nesse caso, a possibilidade de guardar suas mercadorias no próprio ponto.

Denúncias de moradores aparecem como o principal motivo, segundo os comerciantes e prestadores de serviços do bairro, para mudanças do local do ponto; a atuação da fiscalização municipal também é mencionada nesse contexto: por isso, os trabalhadores adotam estratégias para driblar a fiscalização, como a mudança permanente de local ou uma ausência mais prolongada do ponto habitual, ficando vários dias sem aparecer no local de trabalho: "Eu dava um tempo e voltava 
de novo, avisava aos clientes que ia dar um tempo e depois voltava de novo. Botava mais pra frente, botava lá dentro da rua" (Sr. T. T., entrevista realizada em 21 de novembro de 2019).

Percebe-se que quem adota estas estratégias são, em sua maioria, trabalhadores que não realizam o pagamento do DAM (Documento De Arrecadação Municipal): Do universo de 15 entrevistados, apenas 5 declararam pagar o DAM. Quem realiza o pagamento explica como funciona o processo, ou seja, quando o pagamento é realizado e o valor da contribuição:

Uma vez ao ano, [...] esse ano eu paguei... Mais ou menos, eu acho mil e seiscentos ou foi mil e setecentos (Sr. H. B., entrevista realizada em 28 de dezembro de 2019).

É anual, tem documentação e tudo direitinho. Como se fosse um emplacamento de carro [...] Mil e pouco (Sr. S. T., entrevista realizada em 14 de dezembro de 2019).

Por outro lado, quem não efetua este pagamento junto à Prefeitura justifica com a falta de informações para realizá-lo, o receio de perder o ponto atual ao se cadastrar ou que o pagamento da taxa interfira em seus ganhos:

Porque eu já ganho pouco, imagina se eu pagasse alguma taxa? Aí que eu não ia ganhar nada mesmo. O pouco que eu ganho só dá para comprar o pão de cada dia. Não vou mentir, já faz tempo que quero sair dessa vida de vendedor ambulante, eu acho que é porque eu não estou sabendo administrar o dinheiro direito (Sr. F. B., entrevista realizada em 11 de dezembro de 2019).

Nunca me deu essa informação, então nunca fui para me cadastrar, também se a gente se cadastrar, eles podem dar um ponto pra gente e aí vamos depender do local que eles vão dar porque eles podem me colocar num bairro que eu não tenho hábito de trabalhar, não tenho freguesia e aí vou ter que começar do zero. Aqui eu já tenho muitos fregueses, eu tenho fregueses que vêm de vários locais porque já sabe que a gente trabalha aqui (Sra. B. P., entrevista realizada em 30 de novembro de 2019).

Sobre a requalificação do largo da Graça os comerciantes e prestadores de serviços de rua não acham, como no depoimento a seguir, que isso influenciou seus negócios:

Esse negócio de reforma não influi em nada porque hoje o comércio tá parado, sei lá... O povo não quer gastar, entendeu? O povo prefere usar mais cartão, usar mais coisas parceladas, compra menos e acaba gastando menos na rua, entendeu? Por isso que o comércio deu essa queda aí. Não é por reforma de nada (Sr. T. T., entrevista realizada em 21 de novembro de 2019).

Mesmo para quem trabalha no Largo da Graça (onde se concentrou a última operação de requalificação no bairro) ou em seu entorno, as respostas não foram diferentes: "Mudou não, continua no mesmo. A reforma não interferiu em nada" (Sr. S. T., entrevista realizada em 14 de dezembro de 2019); "Não, não mudou em nada” (Sr. H. B., entrevista realizada em 28 de dezembro de 2019). 


\subsection{O pontapé inicial: como os comerciantes e prestadores de serviço do bairro da Graça adquiriram dinheiro para começar a trabalhar}

Percebeu-se uma característica fundamental do perfil de quem trabalha no bairro da Graça: a maneira como adquiriram os recursos para o investimento. As respostas de nossos entrevistados corroboram as características do circuito inferior da economia urbana, conforme explicitado por Santos (2004, p. 45): "No circuito superior os capitais são comumente volumosos, em relação com a tecnologia utilizada. Ao contrário, no circuito inferior, as atividades 'trabalho intensivo' utilizam capitais reduzidos e podem dispensar uma organização burocrática”. Com um capital inicial próprio reduzido e o uso do trabalho intensivo as particularidades de quem trabalha no circuito inferior da economia se tornam nítidas nas falas dos comerciantes e prestadores de serviço nas ruas do bairro:

Algum vizinho vem e me empresta ou quando minha coroa pode me ajudar, ela me ajuda... Ela me empresta, coloca uma mercadoria pra mim e aí eu vou e trabalho ou ela me dá o dinheiro da guia (Sr. F.B., entrevista realizada em 11 de dezembro de 2019).

Eu comecei trabalhando com os meus primos, aí depois eu juntei dinheiro, comprei a banca e pronto. Eles foram pra outro comércio, hoje trabalham com material de construção ( $\mathrm{Sr}$. B.B., entrevista realizada em 19 de outubro de 2019).

Desde novinho sempre [...] pensei no futuro, então mesmo novinho qualquer dinheirinho que eu ia pegando, colocava na caderneta. Quase que eu não pegava ônibus, só andava a pé e tudo mais... Estudava à noite no Antônio Viera que fica no Garcia e ia andando, eu morava na Graça, na rua Conde Filho (Sr. S.T., entrevista realizada em 14 de dezembro de 2019).

Além disso, fica explícito nas entrevistas o baixo estoque de mercadorias e o pequeno investimento de quem trabalha no recorte espacial analisado. Compra-se pouco e quase todos os dias como explicitado por Santos (2004, p. 215):

O comerciante [...] se reabastece em pequena quantidade e todos os dias, porque tem necessidade de ter um estoque diversificado num pequeno espaço que, além disso, não é equipado para conservar gêneros perecíveis; mas também porque suas possibilidades são limitadas e o colocam na dependência do credito em relação a um atacadista ou semiatacadista e, às vezes, mesmo de um varejista. Ele também só pode comprar em pequenas quantidades.

Um capital inicial próprio (através de ajuda de familiares e amigos, indenização trabalhista, poupança), baixos estoques, investimento pequeno, além de ausência de capital de giro enfatizam o modo particular de como os comerciantes e prestadores de serviços de rua do bairro da Graça conseguiram dinheiro para iniciar sua atividade atual. E, mais uma vez, essas observações em campo encontram respaldo na Teoria dos Dois Circuitos da Economia Urbana (SANTOS, 2004, p. 46):

No circuito inferior, a acumulação de capital não constitui a primeira preocupação ou simplesmente não há essa preocupação. Trata-se, antes de tudo, de sobreviver e assegurar a 
vida cotidiana da família, bem como tomar parte, na medida do possível, de certas formas de consumo particulares à vida moderna.

\subsection{Jornada de trabalho dos comerciantes e prestadores de serviço de rua do bairro da Graça}

Outro traço importante para análise do cotidiano e do perfil de quem trabalha no bairro da Graça é a jornada de trabalho. Observou-se em campo como os comerciantes e prestadores de serviços de rua adaptam suas jornadas de trabalho às suas especificidades: compras que ocorrem quase diariamente, espaços pequenos e falta de estrutura para conservação de produtos perecíveis, que podem acarretar alimentos estragados e, consequentemente, gerar prejuízos, como percebemos no relato do Sr. T.T.: "De segunda a sexta [...] Porque no final de semana o pessoal viaja muito, funcionário não trabalha e aí cai muito o movimento, fruta se comprar e não vender acaba perdendo". Além disso, a fala da Sra. E.B. - "quinta, sexta e sábado [...] Porque é o dia que mais vende, sai mais" - mostra que quem trabalha no recorte pesquisado acredita em melhores dias da semana para as vendas.

Afazeres domésticos ou trabalhar em outros serviços ou bairros são também fatores que modificam a jornada de trabalho, como podemos perceber no relato da Sra. B.P.: "Eu trabalho de terça a sábado porque na segunda-feira eu tiro pra resolver meus problemas de médico ou alguma coisa de casa, trabalho no domingo também, mas trabalho na Feira do Nordeste". Também pode ocorrer de o entrevistado realizar outros serviços de forma esporádica e, por receio de denúncias, trabalhar poucos dias durante a semana como já mencionado.

Os entrevistados que trabalham nas bancas de jornal e revistas contam no seu dia a dia com estruturas fixas e a possibilidade de guardar seus produtos, evitando assim gastos com depósito ou a necessidade de transportar produtos diariamente, com jornadas mais regulares e extensas na semana. Conforme relato do Sr. H.B.: "Todos os dias. De dois anos pra cá, eu não estou trabalhando aos domingos. [...] geralmente no Carnaval, a gente também não abre... Antigamente era todos os dias"; ou de acordo com o Sr. G.T.: "Todos os dias. Segunda a sábado".

Podemos inferir, portanto, algumas diferenças nas jornadas de trabalho, a partir das entrevistas. Os comerciantes e prestadores de serviços que trabalham com frutas e verduras geralmente não têm uma estrutura fixa e precisam comprar seus produtos em feiras populares ou centrais de abastecimento; além disso, é mais frequente que trabalhem em outros serviços ou bairros, adaptando suas jornadas de trabalho às suas necessidades. Os entrevistados que trabalham em bancas de jornal e revistas apresentam uma jornada que reflete a disponibilidade de uma estrutura fixa. 
Percebeu-se certa "fixidez" nos locais escolhidos para estabelecer o ponto, com os comerciantes vendendo seus produtos em estruturas móveis estacionadas, como o fundo dos carros, ou expostos no chão com auxílio de caixotes, montados no começo do dia e retirados à noite, ou, ainda, em barracas de metal, para quem trabalha em bancas de revistas, os chaveiros/sapateiros e alguns poucos vendedores de frutas, havendo, nesses casos, a possibilidade de guardar suas mercadorias e instrumentos de trabalho no próprio ponto.

\subsection{Visão dos comerciantes e prestadores de serviço de rua em relação aos vendedores não cadastrados e moradores de rua, à violência e ao que pode melhorar no comércio}

Temas como assaltos, violência e moradores em situação de rua aparecem nas falas dos entrevistados quando discorrem sobre os desafios e dificuldades de se trabalhar no recorte pesquisado:

Hoje [...] a violência está muito grande... Cresceu muito... motoqueiro roubando, pivete que entra na banca pra roubar [...] Não, morador de rua não... É mais delinquente mesmo que vem pra roubar, furtar porque aqui a gente vê muito, motoqueiro que toma bolsa ou celular das pessoas (Sr. G.T., entrevista realizada em 14 de dezembro de 2019).

O que mais tem aqui é gente de rua, sabe? Aqui tem mais morador de rua que ladrão [...] Um dia desses, há pouco tempo atrás, eu estava aqui com mais quatro, comendo uma merenda, aí o cara me chamou, ali naquele poste, e aí eu fui, o cara puxou a arma pra mim e pediu vinte reais. [...] Ele só queria esse dinheiro, aí eu peguei vinte reais e ele foi embora. Aí os caras ficaram dizendo pra mim que não, que a gente pegava ele. Só que ele $[\ldots]$ só queria os vinte reais. Agora de rua tem muito, a gente já tá acostumado (Sr. D.C., entrevista realizada em 01 de novembro de 2019).

Outro problema são os vendedores não cadastrados:

Eu vendo um lanchezinho pequeno, né? Tem lanche aqui na frente, um pessoal que não paga imposto nem nada... [...] Eu não reclamo e nem digo nada [...] Aí eu vou reclamar, o cara vem e me dá uma facada, mata você, então é melhor viver na harmonia com todo mundo [...] eu concordo que todo mundo deveria pagar porque se eu pago pra poder ter o meu negócio aqui, os outros também estão usufruindo de lucros (Sr. H.B., entrevista realizada em 28 de dezembro de 2019).

Segundo Santos (2004), não podemos caracterizar os dois circuitos da economia urbana através de variáveis isoladas. Antes, é necessário considerar o conjunto dessas atividades. Dessa forma, apesar de focar a análise nos comerciantes e prestadores de serviços de rua do circuito inferior da economia, sabe-se que os dois circuitos se relacionam e essa relação é visível no universo pesquisado. Alguns comerciantes e prestadores de serviço acreditam que uma melhora do comércio e dos serviços do circuito superior no bairro poderia trazer também mudanças positivas para o comércio e os serviços de rua do circuito inferior.

Outros apontam que o problema é a crise econômica que causa desemprego e consequentemente traz mais pessoas para o comércio de rua, gerando mais concorrência, como se 
percebe no relato do Sr. S.T.: "Não vejo expectativa de melhorar não porque a concorrência tá grande, a tendência é a concorrência aumentar e o desemprego tá muito alto, aí a pessoa se desemprega [...] vai fazer alguma coisa no comércio e aí a tendência é ficar superlotado!”. O crescimento do circuito inferior, aqui representado pelo comércio/pelos serviços de rua, em momentos de crise, se dá porque esse circuito (o inferior) é o verdadeiro fornecedor de ocupação para a população pobre da cidade e os migrantes sem qualificação (SANTOS, 2004). Tudo isso está ligado às condições tecnológicas e financeiras das atividades desse setor e a suas relações com o conjunto da economia urbana.

\section{O BAIRRO DO RIO VERMELHO}

\subsection{O Comércio de Rua do Rio Vermelho: o Largo da Mariquita e a Rua da Paciência}

No Rio Vermelho a maioria dos comerciantes e prestadores de serviço de rua tem idade entre trinta e sessenta anos. O grau de escolaridade oscila entre o fundamental incompleto e o médio completo. Durante as entrevistas, foram encontrados dois empreendedores com ensino superior incompleto, entre eles um estudante de pedagogia, que necessitou realizar o trancamento da universidade para conseguir dinheiro e sobreviver; outro comerciante vive uma vida dupla de trabalho e estudo, cogitando transformar seu trabalho em um projeto de extensão da universidade.

Observou-se que o comércio de bebidas, aqui denominado de "Guia de bebidas" ("guia" é o termo usado pelos comerciantes para identificar qualquer estrutura, móvel ou não-móvel, na qual se coloca as mercadorias à venda), é o predominante no bairro, por conta de seu "perfil boêmio". O número de comerciantes desse ramo é crescente e cada vez mais concorrido pela facilidade de compra e venda dos produtos. Os comerciantes que vendem comida, apesar da variedade, são minoria, sendo as carrocinhas de cachorro-quente as mais frequentes. Uma questão que mais à frente será discutida é a impossibilidade de vender outros tipos de mercadorias e a taxação sobre o ponto de vendas.

Constatou-se que os comerciantes dos estabelecimentos instalados em quiosques no Largo da Mariquita ${ }^{6}$ e com "porte de empresa"7 estão presentes nos sete dias da semana e que o mesmo não ocorre com os pequenos comerciantes, que estão presentes nos fins de semana e feriados festivos, quando as casas de show abrem as portas e o fluxo de pessoas se torna mais intenso. Em campo observou-se que os maiores consumidores nesses negócios são grupos de jovens e adolescentes, mas há também a presença de pessoas mais velhas que buscam alternativas de consumo "mais baratas".

\footnotetext{
${ }^{6}$ Situação similar à verificada no bairro da Graça para aqueles que dispõem de estruturas metálicas fixas (bancas de revistas, de frutas, de lanches ou de serviços de chaveiro/sapateiro).

${ }^{7}$ Esses estabelecimentos possuem estrutura de uma microempresa, com funcionários e divisão de encargos/tarefas.
} 
O tempo de trabalho desses comerciantes varia bastante: há pessoas que estão no ponto há três meses e pessoas que afirmam estar há quarenta anos trabalhando nas ruas do bairro. Quando se questiona a maneira como os produtos são transportados, percebe-se que o uso do transporte fretado ou do transporte público é frequente, assim como a utilização de depósitos ou de transporte manual (como a carrocinha de cachorro-quente que possui rodas). O uso do carro próprio apareceu apenas para os negócios de maior porte.

O fator mobilidade está diretamente ligado ao acesso às mercadorias que são revendidas na orla: os comerciantes não compram suas mercadorias no bairro do Rio Vermelho por conta do alto valor dos produtos comercializados ali. O desafio de encontrar preços acessíveis para revenda parece ser um problema mais urgente para aqueles que utilizam os mercados atacadistas, porém não é tão premente para outros comerciantes que utilizam os depósitos de bebidas para repor seu estoque, revelando uma relação desigual entre os circuitos inferior e superior da economia urbana (SANTOS, 2004). Esse fenômeno pode ter relação com o caráter imediatista do comércio de bebidas e a alta concorrência, já que os comerciantes não dispõem de tempo para realizar pesquisas de preço.

O desemprego, a briga por espaço e a constante luta para conseguir seu sustento é apenas a "ponta do iceberg" dos problemas que esses empreendedores precisam enfrentar. Segundo os relatos dos comerciantes e prestadores de serviço, ao menos uma vez por semana eles se veem obrigados a abandonar seus pontos de trabalho por conta das ações dos fiscais da Secretaria Municipal de Ordem Pública, a SEMOP, o órgão responsável pelo ordenamento e pela fiscalização desses negócios. A SEMOP age como os "olhos" da Prefeitura quanto ao cumprimento das regras impostas para aqueles que trabalham utilizando o espaço público, mas o que é cobrado, na maioria das vezes, é o pagamento obrigatório do Documento de Arrecadação Municipal, o DAM, uma forma de garantia sobre o ponto e sobre os produtos que serão comercializados. Porém, os dados coletados em campo mostram que a maioria dos comerciantes não realiza esse pagamento.

Os comerciantes justificam que não pagam essa taxa por conta da ausência de garantias que ela apresenta, outros argumentam que estão tentando pagar o DAM, mas não há mais nenhuma possibilidade de realizar cadastros de comerciantes de rua no bairro do Rio Vermelho. Já os comerciantes que afirmam pagar os cento e cinquenta reais de DAM não deixaram muito claro se é a autorização para funcionamento do ponto ou se é o valor cobrado pelo cooler padronizado da Prefeitura (de uso obrigatório). Entre aqueles que realizam o pagamento do DAM, as queixas estão focadas nas regras da SEMOP sobre o ordenamento de seus negócios. Alguns comerciantes se queixam da impossibilidade de vender bebidas nos pontos, outros afirmam que foram impossibilitados de utilizar cadeiras ou lonas: 
A gente não tem disponibilidade de botar mesas e nem cadeiras, porque barraca de acarajé não pode. Aí a gente conversou lá e a gente coloca, às vezes eles vêm aqui e procuram o documento. Eles levaram o toldo grande que a gente tinha aqui, que era pra parar a chuva e pros fregueses ficarem, porque não pode. Lá (Dinha) tem cadeira porque lá é bar, é cadeira do bar. Então eles pararam de pegar no pé da gente, mas por um tempo pegavam e pegavam muito. Aí teve uma vez que chegaram dez aqui, tudo já com os policiais, para os rapazes que trabalham aqui não revidar. Mas é difícil, eles não deixam ninguém trabalhar (Sra. E.D., entrevista concedida em 25/10/2019 - Rua da Paciência).

Algo que aparece como grande problema é a abordagem dos fiscais, quando não são incomuns flagrantes de correria, produtos sendo apreendidos e brigas nas noites do Rio Vermelho. Esse mesmo tema ressurge quando discutimos os desafios de trabalhar no bairro, pois o conflito entre os agentes públicos e os comerciantes tende a superar outros problemas como a crescente concorrência e a criminalidade:

Eu não saio daqui! Quando o agente tira as fotos, eu fui lá e era pra saber quem é que fica aqui vendendo direto e quem não fica. Tá surgindo uma conversa aí que tá trocando os coolers. Quem não pagar, eles vão levar. Aí se eles levarem eu vou fazer o quê? Vou botar isopor e ficar correndo deles? Eu já corri muito, já sai correndo ali (em direção ao Largo da Mariquita), bateu minhas pernas e a cerveja virou pelo chão, e eles passando de Kombi dando risada (Sra. D.C., entrevista concedida no dia 16/11/2019 - Rua da Paciência).

A partir das entrevistas, percebe-se que os conflitos existentes no Rio Vermelho não eram tão frequentes antes da requalificação da orla. Com o aumento do número de vendedores trabalhando na informalidade, o poder público passou a agir com maior frequência. Há quem questione a qualidade da requalificação e há quem elogie: os comerciantes localizados na Rua da Paciência afirmam que a calçada já está com problemas de estrutura, assim como alguns equipamentos foram mal colocados. Em contrapartida, os comerciantes localizados no Largo da Mariquita acreditam que a requalificação foi a melhor coisa que poderia ter acontecido ao bairro:

Caiu mais ainda, o pessoal gostava como tava, do jeito que tava. Mas não adiantou, olha pra isso? Tá tudo quebrando de novo, o povo tá tropeçando e quebrando a cara, um dia desses um rapaz tropeçou aqui e quase foi parar na frente do carro (Sra. C.B., entrevista concedida no dia 16/11/2019 - Rua da Paciência).

Foi a melhor coisa que aconteceu. [...] Aqui não tinha praça, e, como faltava muita energia, quando chovia os postes pegavam fogo, então a preocupação da gente era essa. [...] tinha briga de um pessoal que tomava conta de carro, não tem mais isso, você botava seu carro e eles queriam dez reais, agora você paga três reais e se quiser mais horas paga seis reais, então vale à pena, tem policiamento o tempo todo aqui (Sra. L.J., entrevista concedida no dia 25/10/2019 - Largo da Mariquita).

\subsection{O comércio de rua e a criminalidade: as dificuldades de manter um negócio diante da violência urbana}

Durante o período de realização das entrevistas, observou-se que a criminalidade era um assunto que constantemente aparecia nas falas dos entrevistados. Não era incomum ouvir dos comerciantes que os assaltos e as brigas estavam se tornando corriqueiros no bairro. $\mathrm{O}$ tráfico de 
drogas a céu aberto também não era incomum, principalmente quando nos aproximávamos de bares, casas de shows ou onde houvesse qualquer concentração de grupos de jovens na rua.

O problema do tráfico não é novidade para o poder público, principalmente em se tratando de assaltos a estabelecimentos comerciais no Rio Vermelho. Em uma matéria do G1, publicada no dia 2 de dezembro de 2019, a Secretária de Segurança Pública anunciou que o bairro lidera em números de assaltos a estabelecimentos comerciais na cidade de Salvador (OLIVEIRA; BRASIL, 2019). Parte desse problema está na diminuição do contingente de policiais, que hoje é de aproximadamente 175 agentes atuando em todo Rio Vermelho, o que aparenta ser um número muito pequeno para a quantidade de visitantes e estabelecimentos no bairro.

Foi checado no site da Secretaria de Segurança Pública (SSP-BA) o número de denúncias realizadas no bairro. Esses números foram distribuídos por classes, sendo elas: homicídio doloso; lesão corporal; latrocínio; tentativa de homicídio; estupro; roubo a ônibus; roubo de veículos; furto de veículo; porte de substância entorpecente. Segundo o portal, essas são as principais formas de delitos, e também são os únicos delitos com dados disponíveis para o acesso público. O grande problema são os números que a SSP-BA disponibiliza, que não contemplam os crimes que ocorrem a pedestres e nem o tráfico de entorpecentes, sendo esses os alvos principais das queixas dos comerciantes e prestadores de serviço de rua no bairro. Então, ao se coletar os dados anuais que vão de 2014 a 2019 e somar as classes de delitos, como pode ser observado na figura 3, percebe-se que, apesar de um aumento nos anos de 2016 e 2017, esses tipos de contravenção não sofreram grandes alterações nos últimos anos (e até diminuíram um pouco em 2019).

Os números apresentados na figura 3 refletem a situação da segurança pública em Salvador, mas pouco dialogam com a realidade do comércio/dos serviços de rua. $\mathrm{O}$ fato de a Secretaria de Segurança Pública não divulgar dados de assaltos e furtos que ocorrem com os transeuntes do bairro mostra que estamos diante de um problema o qual não podemos mensurar com dados quantitativos. Em contrapartida, esses dados servem como um indicativo. A sensação de perigo constante foi apontada diversas vezes pelos comerciantes por ser um problema que os afeta duplamente: além do risco de vida, a diminuição da clientela é quase inevitável.

Quando questionamos sobre a requalificação ou sobre o que os entrevistados gostariam de reivindicar para melhoria do seu ponto, as respostas que apontavam a situação da violência no bairro eram explicitamente alarmantes, como foi o caso de dona Denise, que narrou uma situação de violência contra um idoso na Praia da Paciência:

A vendagem caiu, o tráfico aumentou [...] é roubo, roubo... Quando era no Rio Vermelho velho era tudo por debaixo dos panos. Agora se você quiser entrar ali na placa de Iemanjá você não entra. Ontem mesmo, o velhinho bebendo sentado virado pra lá, quando eu passei pela mulher eu sabia que ela era ladra, pensei: “ai, meu Deus, vão roubar o velhinho", tava ela sentada junto dele, mais um sequinho e outro mais afastado, depois eu vi os três 
descendo correndo aqui, empurraram ele. Ele caiu embaixo do pé de amêndoa, levaram o celular e tudo dele. Eu falei pros policiais, mas eles disseram que não podiam fazer nada. Ele subiu se arrastando, todo se tremendo (Sra. D.C., Rua da Paciência, entrevista concedida no dia 16/11/2019).

É possível que a comerciante Denise tenha descrito a mesma história que apareceu na matéria do G1, quando um dos representantes da Associação de Pescadores do Rio Vermelho afirmou que os turistas estavam sendo arremessados do calçadão para a praia por criminosos que circulam naquele trecho do bairro. $\mathrm{O}$ entrevistado afirma na matéria que a polícia necessita do flagrante para poder agir, e, mesmo nos casos em que consegue deter os assaltantes, eles são liberados logo em seguida. Não podemos afirmar a veracidade dessas afirmações descritas na matéria, mas nossas idas a campo mostraram que a preocupação com os assaltos e furtos é consenso entre comerciantes e transeuntes do Rio Vermelho.

\section{Total de delitos no bairro do Rio Vermelho}

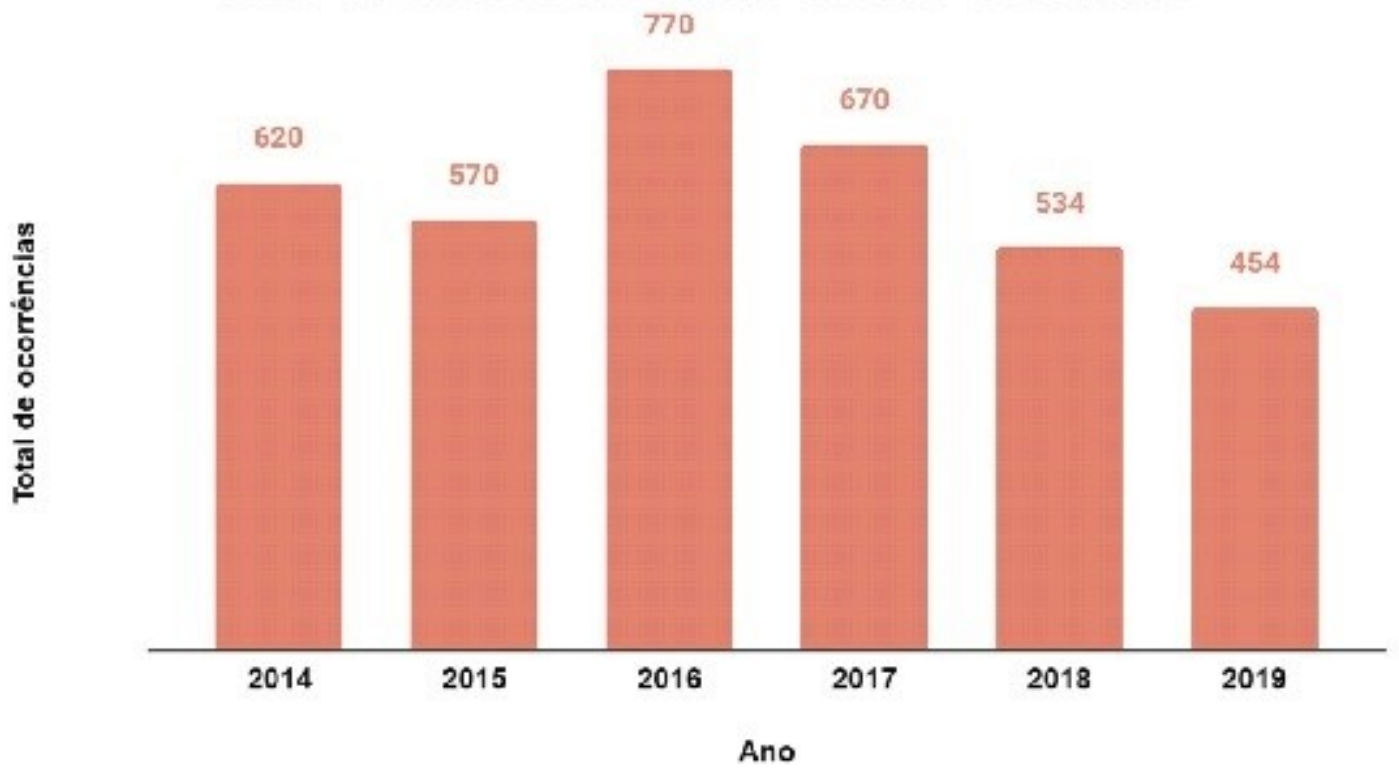

Figura 3 - Total de delitos no bairro do Rio Vermelho.

Fonte: Secretaria de Segurança Pública. LEITE, 2020, elaboração própria.

A fala da comerciante também deixa em evidência o papel que a requalificação assume diante do contexto de violência do bairro, onde, após a reforma, parece não existir mais a preocupação em esconder negociações ilícitas. Porém, tudo indica que essa exposição do tráfico de drogas está mais ligada à diminuição do contingente de policiais na rua, como descrito na matéria do G1. A maneira como o tráfico de drogas se espacializa no bairro aparece como um grande problema aqui, pois, além de ser visto como ameaçador para os comerciantes/prestadores de serviço, é também motivo de constantes conflitos armados e brigas no bairro: 
Aqui a gente enfrenta muita coisa, eu vou falar: a gente enfrenta tráfico [...] tem muita briga, não sei se você soube, mas aqui teve morte, e a gente tá exposta. A gente tá tentando, mas é um risco que estamos correndo, porque a qualquer momento você pode receber uma bala perdida, você não sabe no meio de quem você tá. [...] A gente fica muito exposto a bandido, a vagabundo, a mendigo pedindo toda hora, assalto também porque se a gente vacilar nego assalta, encosta de junto e às vezes mostra a arma. Aqui nunca encostaram a arma não, mas já trabalhei em lugares que já (Sra. C.T., Rua da Paciência, dia 01/12/2019).

Nessa pesquisa não se buscou aprofundar o modo como o tráfico de drogas se territorializa e nem entender os processos socioespaciais através dos quais se sustenta, mas sim como ele afeta negativamente a vida dos empreendedores de rua no Rio Vermelho. Também se percebeu que, apesar da atuação do tráfico estar presente no Largo da Mariquita, é na Rua da Paciência onde ele se concentra. Constatou-se que, durante a realização das entrevistas, os agentes policiais faziam rondas a pé pela Rua da Paciência, porém a presença deles aparentava ser maior no Largo da Mariquita, onde havia uma delegacia móvel estacionada.

\subsection{Regularização do ponto: o comércio informal e o desejo de legalizar seu trabalho}

Vimos até aqui que as dificuldades em lidar com o desemprego e a necessidade de sobreviver são somadas aos incessantes conflitos com os agentes municipais da SEMOP, que são responsáveis pela fisscalização do comércio e dos serviços de rua no bairro. Por conta disso, muitos comerciantes buscam se regularizar junto à Prefeitura.

Durante a realização das entrevistas, percebemos que há dois grupos distintos de comerciantes: aqueles que estavam no ponto antes da requalificação e, por conta disso, foram regularizados e encontram-se fixos; e aqueles que chegaram após a requalificação e não conseguem os documentos necessários que os autorizem a trabalhar no bairro. É interessante perceber nos relatos que esses grupos, apesar de expressarem algum incômodo/desagrado quanto à concorrência, não aparentam entrar em conflito. Porém, ambos possuem formas distintas de se relacionar com a Prefeitura.

Conversando com os comerciantes, percebe-se que a grande maioria deles possui o desejo de ser regularizada, pois buscam dar um basta nessa rotina de assédios e fugas da fiscalização. Porém, esses empreendedores afirmam que não conseguem realizar o cadastro para trabalhar no Rio Vermelho por diversos motivos, seja pela alegação de não haver mais espaço ou simplesmente por conta da estrutura do negócio:

Se eles chegam aqui, a gente tem que sair, porque a Prefeitura infelizmente não disponibiliza para a gente um alvará que a gente possa pagar para a gente ficar trabalhando, pois eles dizem que é por causa da churrasqueira e do fogo, mas isso são coisas que se resolve (Sr. A.Z., entrevista concedida no dia 14/12/2019). 
No Largo da Mariquita, apenas os comerciantes que atuam nos quiosques estão regularizados, todos os outros trabalham sem cadastro. Essa situação é diferente na Rua da Paciência, onde se observou que comerciantes com e sem cadastro dividem espaço, trabalhando na mesma função. O que se pode inferir dessa situação é que o motivo de existir tanta rigidez na fiscalização da praça está ligado a uma alegada impossibilidade de realizar o cadastro de novos comerciantes naquele espaço público, embora ainda não fique clara qual a justificativa do poder público para essa interdição.

A situação na Rua da Paciência aparenta ser diferente, mas ainda assim é muito problemática. Com os comerciantes cadastrados e não cadastrados trabalhando lado a lado, a maneira que a fiscalização encontrou para diferenciá-los está na obrigatoriedade do uso de coolers azuis com o emblema da Prefeitura de Salvador para os vendedores regularizados. Os que não possuem esse material utilizam isopores térmicos e caixotes improvisados. Entre aqueles que não possuem tal equipamento, há o desejo da regularização, como no caso do senhor J.I., que afirma estar aguardando uma resposta da Prefeitura quanto à regularização do seu ponto:

Eu estou correndo atrás, mas até hoje não me deram [...] deram um protocolo, porque na verdade ele diz que aqui não pode vender, que tem que vender do outro lado, mas ninguém nunca sabe onde é. Já tiraram um bocado de retrato, mais de cinco vezes (Sr. J.I., Rua da Paciência, dia 30/11/2019).

Essa forma de regularização do ponto aparenta trazer poucas garantias para os comerciantes que, independentemente de estarem ou não pagando taxas, se veem impossibilitados de possuir uma estrutura que os proteja da chuva e do vento. Além disso, como observado anteriormente, a Prefeitura limita os produtos que serão vendidos nesses negócios. Essa burocracia não é uma exclusividade do Rio Vermelho, mas aparenta ser a maneira através da qual a SEMOP organiza esse tipo de comércio na cidade. Quando questionada sobre os desafios e dificuldades em trabalhar no ponto, uma das comerciantes afirma que está tentando sair do bairro por conta da distância, mas que está impossibilitada por uma questão burocrática:

Eu já pedi transferência à Prefeitura pra me botar em outro lugar durante o dia, onde eu pedi eles disseram que não podiam botar, que era ali onde fica o hospital Irmã Dulce, porque pra mim ali era perto, mas a Prefeitura disse que não pode (Sra. L.J., Rua da Paciência, entrevista concedida no dia 16/11/2019).

Após essa entrevista, a comerciante informou que está pagando por um "DAM de transferência" para que ela possa ser relocada para uma praça recém-requalificada no centro da cidade, mas que ainda não obteve nenhuma resposta da Prefeitura quanto à relocação. Constata-se que a regularização desses comerciantes/prestadores de serviço é tão burocrática (e inacessível) que eles são obrigados a assumir o risco de perderem tudo para a fiscalização, mas com alguma garantia 
de levar o sustento para suas famílias. É uma situação muito semelhante àquela verificada em pesquisas anteriores realizadas pelo Grupo Espaço Livre de Pesquisa-Ação no entorno da Estação da Lapa, onde os comerciantes foram relocados para locais onde não havia movimento, e, assim, se viram obrigados a assumir os riscos de confronto com a SEMOP e voltar para os antigos pontos para alcançarem melhores vendas (SERPA; LEITE; MACHADO, 2019).

Porém, a questão da comercialização de bebidas por vendedores não cadastrados e o cadastramento de novos comerciantes no Largo da Mariquita não foram os únicos problemas que surgiram em relação às regras do uso do espaço público no Rio Vermelho: um dos nossos entrevistados, Anderson, contou que teve dificuldades com a SEMOP quando iniciou seu ponto, porque os agentes da Prefeitura exigiam que ele vendesse seu produto artístico em uma lona no chão junto com os "hippies":

A Constituição não diz como você tem que expor, mas a SEMOP diz que tem que ser no chão, que nem ele que está com a mesinha aqui [...] se a SEMOP vir ele tem que dobrar as pernas porque tem que ficar no chão. É ridículo! Se eu coloco uma mesinha aqui o meu material fica apresentável, não fica sujando no chão. Até alguns clientes perguntam por que eu não coloco em uma mesa, aí eu tenho que explicar a situação (Sr. A.B., entrevista concedida dia 14/12/2019 - Largo da Mariquita).

O problema é que, além da falta de explicação plausível, o decreto municipal n. 12.016, de 08 de junho de 1998, que define como deve ocorrer o uso do espaço público, informa no primeiro parágrafo do artigo 10 que "em nenhuma hipótese será permitido o comércio ambulante e a prestação de serviços nas seguintes condições: com mercadorias no chão, espalhadas sobre lonas, plásticos e papelões" (DIÁRIO OFICIAL DO MUNICÍPIO, 1998). Portanto, há desconhecimento dos próprios agentes municipais quanto às normas do município para o uso do espaço público, ao mesmo tempo em que existe alguma forma de flexibilização da Prefeitura para que essas pessoas possam continuar comercializando nesses espaços.

\section{CONCLUSÕES}

Embora haja especificidades evidentes em cada um dos recortes analisados, percebe-se que em ambos os bairros há uma complementaridade entre os dois circuitos da economia, evidenciada, sobretudo, na localização do comércio e dos serviços de rua, sempre próximos a estabelecimentos comerciais e de serviços do circuito superior, de modo a usufruir do fluxo de transeuntes/consumidores, nem sempre moradores dos dois bairros pesquisados. Nesse contexto, é essencial reforçar que não se trata aqui apenas do bairro das "práticas cotidianas, relações de parentesco e vizinhança, vida comum" (DIAS, 2017, p.16), mas também o bairro onde se vai no intuito de trabalhar (em ambos os bairros a forte presença do circuito superior gera empregos formais de todos os tipos) ou em busca do lazer (bairro do Rio Vermelho), ou ainda para usufruir de 
serviços médico-hospitalares ou laboratoriais específicos (bairro da Graça). Isso tudo mostra como o espaço não é homogêneo e os dois circuitos, propostos por Milton Santos, coexistem dialeticamente e de modo indissociável entre eles.

Observou-se que existe uma relação conflituosa recorrente entre comerciantes e agentes de fiscalização municipal (SEMOP), especialmente no Rio Vermelho, algo que não é incomum em outros locais onde ocorreram operações de requalificação urbana, como se pôde observar em pesquisas anteriores (SERPA; LEITE; MACHADO, 2019). No Rio Vermelho esse conflito ocorre com uma dinâmica própria, sendo a presença e a ação dos agentes da Prefeitura parte da rotina diária desses empreendedores. Observou-se, por outro lado, que a competitividade deu lugar à cooperação entre os comerciantes, pois essa parece ser a melhor estratégia de sobrevivência, frente às operações de controle e organização do comércio nas ruas do bairro. Essa forma de organização imediata foi perceptível in loco, já que os comerciantes passam todo o período de trabalho informando uns aos outros a presença/localização dos fiscais, além de organizarem protestos coletivos como reação à apreensão de suas mercadorias.

A permanência dos comerciantes de bebidas nas ruas do Rio Vermelho, com a condição de que utilizem o cooler cedido pela Prefeitura, aparenta ser uma estratégia do poder público para evitar conflitos como os ocorridos em junho de 2016, quando comerciantes incendiaram pneus e protestaram na Rua da Paciência contra a apreensão de seus produtos. Esse evento, informado por uma das entrevistadas e noticiado pelo portal "Jornalistas Livres" (JORNALISTAS LIVRES, 2016), demonstra que o poder público necessitava encontrar alguma nova estratégia para evitar maiores conflitos e os coolers surgiram como uma resposta possível: permitindo que alguns possam vender e impossibilitando o cadastro de outros, a Prefeitura consegue desmobilizar os comerciantes e, ao mesmo tempo, agir duramente sobre eles.

No bairro da Graça, chama atenção a quantidade de empreendedores de rua que vendem frutas e verduras. Nesse contexto, buscamos identificar também as redes de produção e distribuição (MAIA, 2013) no recorte pesquisado, através dos levantamentos de campo. As entrevistas revelaram que feiras populares e centrais de abastecimento são os locais mais citados. Em geral, transportam suas mercadorias em carros próprios/fretados ou de ônibus. Observou-se ainda que muitos desses comerciantes de rua da Graça expõem suas mercadorias em caixotes que são dispostos nas calçadas ou nos fundos dos carros. A opção para expor os produtos diretamente no fundo dos veículos é uma tática utilizada para evitar apreensão de mercadorias em caso de fiscalização, já que a maioria dos comerciantes não paga taxas ou está cadastrada pela Prefeitura. No bairro da Graça, no entanto, a presença dos fisscais municipais é mais rara e, quando ocorre, é acionada pelos próprios moradores. 
Em ambos os recortes analisados, os comerciantes/prestadores de serviço apresentam em geral certa flexibilidade em sua jornada de trabalho, adaptando o período de trabalho às especificidades de quem trabalha na rua: compras quase diárias, espaços pequenos, falta de estrutura para conservação de produtos perecíveis, além de seus próprios afazeres domésticos ou por trabalharem em outros serviços. Temas como assaltos, violência urbana e moradores em situação de rua apareceram nos depoimentos, nos dois bairros pesquisados, quando se buscou esmiuçar as dificuldades e os desafios de quem trabalha nas ruas. Tanto no Rio Vermelho como na Graça, aqueles comerciantes/prestadores de serviço que dispõem de estruturas fixas (quiosques e barracas metálicas) são em geral cadastrados e recolhem taxas, além de ter uma jornada de trabalho melhor distribuída na semana e menos dificuldades no cotidiano.

Observou-se que as operações de requalificação urbana empreendidas pela Prefeitura em ambos os bairros foram diferentemente percebidas e vividas pelos comerciantes/prestadores de serviço de rua: no bairro da Graça, a reforma do largo principal e da Avenida Euclides da Cunha não teve, na opinião dos entrevistados, impacto significativo sobre suas atividades e praticamente não foi notada por quem trabalha na rua no recorte analisado. No Rio Vermelho, ao contrário, a requalificação do Largo da Mariquita e da Rua da Paciência, na Orla do bairro, parece ter afetado mais as atividades dos empreendedores de rua, embora divida opiniões entre os entrevistados, já que alguns ressaltaram seus aspectos negativos, enquanto outros valorizaram mais seus aspectos positivos em relação a seu cotidiano no bairro.

Finalmente, fica evidenciada também a dependência dos comerciantes de rua em determinados setores, sobretudo o de venda de bebidas, como no caso do Rio Vermelho, do comércio atacadista e das empresas distribuidoras, que vão funcionar, como destacado por Xavier e Castillo (2011, p. 7) como "um intermediador ${ }^{8}$ entre os dois circuitos", a análise de suas operações permitindo a compreensão, a partir do subsistema da distribuição, "que não há dualismo entre os dois circuitos da economia urbana, mas uma relação dialética de conflito e cooperação" (XAVIER; CASTILlO, 2011, p. 7). Assim, os dois circuitos se constituem como consequência "das mesmas modernizações que a cada momento recompõem a totalidade da formação socioespacial e se comunicam segundo situações complexas em que coexistem diferentes sistemas de produção, distribuição, consumo e emprego" (XAVIER; CASTILLO, 2011, p. 7).

\footnotetext{
8 “Este intermediário - atacadista ou proprietário de caminhão - age como um elo entre a demanda e a oferta que, por sua vez, possuem tempos e quantidades diferenciados, conferindo ao atacadista um papel privilegiado no abastecimento. Isso ocorre porque, no início do mês, ele pode adquirir de seu fornecedor um grande volume de mercadorias que, estocada por ele, poderá ao longo das semanas ser distribuída de forma a atender às demandas dos varejistas, segundo quantidades e frequências variáveis. Sendo assim, ele se diferencia dos comerciantes do circuito inferior, cujos reduzidos estoques são apenas compostos pelo necessário para atender a uma clientela que compra pequenas frações no dia a dia" (XAVIER; CASTILLO, 2011, p. 7).
} 


\section{REFERÊNCIAS}

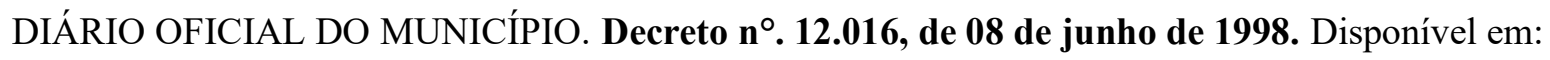
$<$ http://www.ordempublica.salvador.ba.gov.br/images/ComercioInformalEspacoPublico/DecretoN12016Co mercioInformal.pdf $>$. Acesso em: 08 ago. 2020.

DIAS, C. Práticas Socioespaciais e Processos de Resistência na Grande Cidade: Relações de Solidariedade nos Bairros Populares de Salvador. 2017. 285 f. Tese (Doutorado em Geografia) - Instituto de Geociências, Universidade Federal da Bahia, Salvador, 2017.

JORNALISTAS LIVRES. Após apreensão de mercadorias, ambulantes fazem protesto em Salvador. Salvador, dia 18 de junho de 2016. Disponível em: <https://jornalistaslivres.org/apos-apreensao-demercadorias-ambulantes-fazem-protesto-em-salvador/>. Acesso em: 08 ago. 2020.

OLIVEIRA, E.; BRASIL, B. Rio Vermelho é o bairro com maior número de assaltos a estabelecimentos comerciais, aponta SSP. G1. Salvador, dia 2 de dezembro de 2019. Disponível em: $<$ https://g1.globo.com/ba/bahia/noticia.rio-vermelho-bairro-com-maior-numero-de-assaltos-aestabelecimentos-comerciais-em-salvador-aponta-ssp.ghtml>. Acesso em: 08 ago. 2020.

MAIA, A. C. N. Circuitos e redes do comércio de rua em Salvador, Bahia: Uma análise geográfica. 2013. 131 f. Dissertação (Mestrado em Geografia) - Instituto de Geociências, Universidade Federal da Bahia, Salvador, 2013.

MONTENEGRO, M. R. La economia pobre de São Paulo em sus relaciones com la técnica, la información, el consumo y las finanzas. In: SILVEIRA, M. L. (Coord.). Circuitos de la economía urbana. Ensayos sobre Buenos Aires y São Paulo. Ciudad Autónoma de Buenos Aires: Café de las Ciudades, 2016. p. 357-388.

NUCCI, J. Di. División del trabajo y segmentación de la economía urbana em Buenos Aires; bebidas gaseosas y aguas saborizadas. In: SILVEIRA, M, L. (Coord.). Circuitos de la economía urbana. Ensayos sobre Buenos Aires y São Paulo. Ciudad Autónoma de Buenos Aires: Café de las Ciudades, 2016. p. 153186.

SANTOS, M. O Espaço Dividido. 2. ed. São Paulo: EDUSP, 2004. 440p.

SERPA, A.; LEITE, W.; MACHADO, J. Na praia e no centro: Comércio e serviços de rua frente a operações de requalificação urbana em Salvador-Bahia. Caderno de Geografia, Belo Horizonte, v. 29, n. 59 p. 978996, 2019.

XAVIER, M.; CASTILLO, R. A reprodução do atacado distribuidor como um elo entre os dois circuitos da economia urbana no Brasil. GEOUSP - Espaço e Tempo, São Paulo, n. 29, p. 3-17, 2011.

Trabalho enviado em 21/12/2020

Trabalho aceito em 22/01/21 